\title{
A GRANDE TRAVESSIA: textos académicos para gente do risco e do movimento ousado
}

António Henriques

\author{
Universidade de Lisboa - ULisboa, Portugal
}

\begin{abstract}
Resumo
Este texto sugere que o investigador em ciências humanas não existe sem o escritor. A investigação está ligada à prática da escrita e o escritor é o executante da linguagem. Contudo, a linguagem precede-o e não existe um estado em que o investigador possa separar-se da linguagem. Essa consciência obriga a pôr em causa a alegada neutralidade de uma escrita científica ou académica. Na companhia de Maurice Blanchot, Michel Foucault e Roland Barthes, imagina-se o investigador às voltas com a investigação, cujos resultados não podem deixar de refletir, também, um trabalho da escrita e uma ocupação com a linguagem. Supõe-se que o investigador centrado no arquivo, interessado no método e absorvido pelo estilo, vive uma obsessão na procura pelo texto. O texto é a apropriação de todo o caminho da pesquisa.
\end{abstract}

Palavras-chave: Arquivo; Escrita académica; Linguagem; Texto.

\begin{abstract}
This text suggests that the researcher in humanities cannot exist without the writer. Research is linked to the practice of writing and the writer is the performer of the language. However, language precedes him and there is no state in which the researcher can separate himself from language. This consciousness forces us to question the alleged neutrality of a scientific or academic writing. With Maurice Blanchot, Michel Foucault and Roland Barthes, I imagine the researcher struggling with the investigation, whose outcomes must reflect, also, a work of writing and an occupation with language. An archive-centered researcher, interested in the method and absorbed by the style, experiences an obsession in the search for the text. The text is the appropriation of the entire research path.
\end{abstract}

Keywords: Archive; Academic writing; Language; Text. 


\section{Introdução}

Uma escrita académica ou científica sem dúvida se reconhece pelos protocolos aplicados: um tom formal, o uso da terceira pessoa, sempre o foco no problema de investigação, dirigindo-a para o conjunto de iguais que a podem compreender. $\mathrm{O}$ registo da linguagem, a determinação de um léxico ou as formalidades de sintaxe parecem contribuir para distanciar o pesquisador da pesquisa, destinando-a a inscrevê-la no campo imparcial da ciência. $\mathrm{O}$ trabalho sobre a linguagem empreendido pelos autores chamados a este texto, e por muitos outros, lembra que a linguagem pela qual o estudante e o investigador se expressam, e o texto que inventariam a partir do arquivo dos discursos existentes, faz falar ou escrever tanto quanto constrói a mesma fala ou escrita. E sustenta que nenhuma coleção de discursos nem conjunto de enunciados (que é uma escolha de entre os discursos existentes) vive sem ser no cruzamento de outros, nenhum locutor é a origem do seu discurso, nenhum elemento do discurso, som ou unidade mínima de uma escrita, existe sem se remeter, infinitamente, a outro. A pesquisa em ciências humanas não projeta a figura do estudante ou do investigador para o campo das verdades a toda a prova, mas para o desconhecimento de toda a intencionalidade, finalidade e linearidade da prova material e histórica que é escavada.

Esta divergência em relação a uma alegada procura da respeitabilidade útil do saber, que seria a condição para uma escrita formal e distanciada, implica o estudante no desconhecimento do objeto a pesquisar. A escrita que resulta da pesquisa pode, pois, declarar-se como um desassossego, um desassossego em busca de um prazer.

\section{Primeiras perguntas}

O que é a escrita destinada a desvendar os mistérios da narrativa, isto é, o que é a escrita que nos convida a desaparecer nela para que a escrita apareça em nós? A questão não é um aliciamento para um puro jogo de palavras nem os mistérios da narrativa se destinam a jogar mais com as palavras do que os escritores jogam com o seu destino, ao escrever. Evoco os mistérios da narrativa para melhor poder assemelhar uma escrita, que se destina a partilhar uma investigação no âmbito da vida universitária, como se ela fosse uma carta de amor, isto é, como se a escrita fosse o próprio destino de escrever e não apenas a escrita de um objeto determinado.

Por mistérios da narrativa entendo a necessidade de colocação em jogo de perguntas, cujo esclarecimento serviria para desocultar as questões mais difíceis que os pretendentes a escrever enfrentam. Se eu me dirijo para a escrita, o que procuro ao escrever, que movimento desejo pôr em marcha? Os autores que falam do movimento da escrita, como Maurice Blanchot, falam inequivocamente do encantamento pelo desconhecido e do receio pela perdição. Tal seria o destino dos navegadores ao dar ouvidos ao canto das Sereias, que Ulisses teria quebrado com astuciosas manobras para permanecer surdo e imóvel. Impelido pelo canto deslumbrante e sem se afundar nele, Ulisses teria podido gozar o espetáculo visual e 
sobreviver à fascinação das Sereias, dominando essas potências abismais através do "poder da técnica" (BLANCHOT, 2005, p. 4-6).

A escrita que nos convida a desparecer nela, sem sabermos exatamente o que é, conviria que a chamássemos técnica? Existe uma luta travada nas profundezas das consciências dos estudantes que, em alguma área das ciências humanas, para só falar destas, querem escrever no contexto do Ensino Superior (investigar para escrever e escrever para investigar). Sou capaz de pôr-me a caminho? O que posso acrescentar? Vou ter de ler tudo o que existe acerca do meu objeto? Quando é que sei que alcancei o novo? Vou soçobrar à minha mediania? A superabundância destes e de outros dilemas conflui para um centro imaginário, a escrita que o estudante antecipa, e factual, pois é preciso criar um texto, a partir do espaço dos discursos possíveis.

Para que o estudante ou investigador possa estabelecer as condições de uma pesquisa e desenvolver um texto, são necessários o enfrentamento com a ciência e com a sua metodologia, com as escolas de pensamento, com o conhecimento acumulado, com os campos experimentais e o enquadramento em programas de pesquisa. Esse enfrentamento com toda a matéria ensinável, isto é, com a ciência que existe, é um encontro com uma pluralidade de discursos, a partir dos quais conceber o seu próprio torna imperioso frustrar a ideia de a escrita ser apenas o pobre instrumento do discurso científico e o veículo da sua disseminação. A ciência é um discurso, como lembra Barthes, não inocente. A ciência é um discurso e a linguagem através do qual ele se formaliza e faz aparecer o escritor, precede-o em toda a extensão e dificilmente torna a ciência o lugar das descobertas neutras. "Recorrer ao discurso científico como a um instrumento do pensamento é postular que existe um estado neutro da linguagem" (BARTHES, 1987, p. 16). A ciência, pelo menos a ciência das ciências humanas, não é um lugar neutro nem é a região das descobertas para além do bem e do mal, como se fossem inanimadas as suas paisagens. É um lugar em que a linguagem constantemente se debate com o objeto da investigação, formando-o ao descobri-lo e construindo-o ao desvelá-lo.

A negação do conhecimento como uma representação nítida e objetiva da realidade deve muito à investigação sobre os fundamentos da linguagem. Uma tentativa incessante da compreensão da escrita e da produção de textos deslocaram a autoridade do sujeito, do controlo sobre as leis que o regem, das razões do comportamento que assume e das formas de linguagem que o personalizam. Uma vez que o gesto da investigação parte necessariamente do que existe, puseram em causa um tipo de relação com o passado, deslocando para um campo de consequências imprevisíveis a autoridade da consciência, a centralidade do sujeito e a força das origens. Nem consciência que o tempo pudesse abrigar, nem sujeito consciente que a história pudesse atrair para o seu centro, nem origem que pudesse recuar à sua inacessibilidade, mas as representações do pensamento e as resoluções da escrita para empreender movimentos por meio do recorte, do esquecimento, da rotura, da reelaboração, da descontinuidade.

Talvez o que seja possível acrescentar na pesquisa se encontre na implicação entre textos descontínuos; talvez o jogo entre esses textos, que o estudante religa pela primeira vez, o dispense de ler tudo o que existe; talvez a novidade ocorra ao isolar textos que, reagrupados, 
fogem às ideias do sujeito falante: esse trabalho põe em causa as grandes unidades que deviam reconstituir um passado, reconhecer uma origem, perpetuar uma continuidade ou resgatar uma evolução, de tal forma que pode supor-se que o trabalho já se deslocou da mediania do pesquisador para a riqueza da pesquisa. Nesse sentido, narrativa (saber, ter conhecimento de algo, do sânscrito gnärus) e "narro" (contar, relatar) é sinónimo de "metamorfose" e de "movimento em direção a um ponto" desconhecido (BLANCHOT, 2005, p. 8-11). Mesmo que incorpore o campo da Educação, o discurso científico ou académico não se destina a ensinar, mas a retirar do seu território as evidências compassivas, a permutar uma matéria trabalhável, a transitar por fluxos, a flutuar numa superfície vidrada em que o reflexo do escritor mal se descobre.

\section{Tornar-se escritor}

Argumentar que o objeto escolhido para pesquisa só pode ser comunicado pela linguagem, e que a linguagem não é inocente nem neutra nem branca, é somente constatar que o discurso da verdade, que deve ser procurado, é um mar rodeado de bancos de areia, em relação aos quais a aplicação da velha arte da pilotagem deve, pelo menos, saber cartografálos. "Só a escrita é capaz de quebrar a imagem teológica imposta pela ciência, recusar o terror paternal difundido pela 'verdade' abusiva dos conteúdos e dos raciocínios, abrir à investigação o espaço completo da linguagem” (BARTHES, 1987, p. 17).

A linguagem não é um instrumento de que o estudante ou o investigador se vai socorrer, mas a potência que o faz determinar-se, na sua história e na sua biologia. Quando se faz uma afirmação, não se faz apenas incisões, à maneira de um cirurgião, a afirmação tinge-se de significações e de referências, a maior parte das quais talvez escape ao enunciador. O campo enunciativo também não é uma arena entre discursos dominantes e discursos silenciados, entre poderosos e oprimidos, entre discursos que se submetem ao poder e os que o afrontam, mas a superfície em que a complexidade das coisas ditas e ocultadas produzem o poder e o minam, redistribuindo a sua força e modificando a sua implantação. Um convite pode fazerse aos estudantes que querem investigar, um convite e não uma promessa oca: tornarem-se escritores, isto é, escrever a sua pesquisa à medida que se escrevem a si mesmos, abolindo a linguagem como objeto ou mero instrumento, colocando-se no risco de desaparecer a cada frase, para fazer aparecer as questões de toda a enunciação; explicitarem a sua metodologia (e explicitarem-na para si próprios é escrevê-la para os outros), dotarem-se de todo o rigor e de toda a objetividade, como ferramentas perenes e não como fins.

A questão que um estudante universitário se pode colocar no início do seu percurso será em que medida os seus professores (ou mestres) podem cooperar para que ele reclame a sua transfiguração, de estudante em escritor e de aprendiz em estudante emancipado, podendo evocar a tradição de Universidade como corporação de mestres e estudantes que mutuamente se procuram para iniciar uma conversa. Idealmente resguardado por essa cumplicidade dos mais velhos, o estudante pode desejar, publicamente, escrever e, secretamente, apaixonar-se pelo seu objeto. Tudo o que ouve passa a submeter-se à necessidade de enformar esse objeto, 
para afirmar ou negar alguma coisa que lhe diga respeito, para o excluir dele ou para o cimentar. Uma obsessão deve tomar conta do seu dia e, armado de silêncio e reserva, pois não se ouve no tumulto nem se pensa na espuma dos dias, põe-se a caminho fazendo da sua nova ocupação um tempo livre. Esta obsessão trata de descobrir até que ponto se pode pensar de forma diferente daquela que se pensava. É a obsessão pela única curiosidade que vale a pena: "não aquela que procura assimilar o que é conveniente conhecer mas a que nos permite desprendermo-nos de nós próprios” (FOUCAULT, 1994, p. 14).

Por sobre o tempo dos acontecimentos quotidianos, ocupado com o ruído, o tempo da escrita, deixado vago como a página. Experimentar esse tempo como exterioridade, uma criação que é simultaneamente uma espera, aberta para o universo e inacessível à mundanidade e às presunções do dia; e que é um ofício, com o seu ritual de repetição e perseverança. É nessa exterioridade que a pergunta de pesquisa se separa, para em cada manhã ser aclarada. $\mathrm{O}$ estudante pergunta, recomeçando o movimento de todas as perguntas do passado, filiando-se em todos os estudantes que do passado ousaram perguntar, até que a pergunta, longe de clarificar com o seu esclarecimento, ilumina e alegra o perguntador. O que quero saber ao certo? Sou capaz, na minha intimidade, de determinar por que quero saber? Qual é a pergunta que, ao fazer-se, pode deslocar as fundações do que já pensava? Pela primeira vez, imagino que a Educação não foi sempre idêntica ao edifício no qual vivi, que a história do ensino exigiu uma complexidade metamórfica notável, que estou vinculado a planos que me superam e aos paradigmas de ordem geral que não só interiorizei sem grande consciência como me constituem abundantemente.

Como material empírico para trabalhar, o estudante pode desejar entrelaçar aos discursos existentes o seu, sublinhando que a ciência se faz edificando um corpo e inscrevendo um desejo. Edifica-se um corpo através de uma apropriação do material selecionado e analisado, que pode ser objetivado nas circunstâncias que o determinam, mas que não é objetivo, e que pode e deve ser rigoroso, mas não é exato. Desse corpo, o estudante não pode excluir-se, já que é sujeito do seu manuseamento. Ele está implicado na linguagem que o implica, ele não é produtor de uma verdade que o transcenderia e que faria da linguagem um ornamento. Inscreve-se um desejo para percorrer por ele a linguagem com que se elabora o objeto da pesquisa, mais precisamente, para deslocar com ela o sentido do objeto dado inicialmente, renegando qualquer estatuto superior à viagem da escrita e denegando a aquisição de uma verdade estável, formal e decisiva.

\section{Fuga à autoridade}

A noção de mistura do antigo com o que há de vir tende a quebrar a ideia de homogeneidade, o pretenso acabamento, a justiça da última sentença, a norma pela qual foram classificados os discursos, um certo artifício em que repousam. É para os atravessar que o estudante os observa na sua repetição, esquecimento e transmutação, nos jogos de poder que os tentam justificar. É tanto a manutenção dos discursos desconforme a qualquer lei quanto a sua dispersão em favor do seu enaltecimento, que é preciso captar na travessia. 
Se a discursividade é o campo em que instrumentos e efeitos de poder se entrecruzam, talvez o estudante possa procurar a exploração de um domínio do conhecimento de forma livre, não esquecendo que não há objeto do conhecimento nem centro de saber que devam a sua existência ao desinteresse e à liberdade, mas às potências e fraquezas que construíram a sua história. Se os programas de investigação existentes nada devem a uma neutralidade ou isenção com que teriam sido criados (existem na determinação prévia das instituições que os oferecem), o combate às limitações que eles implicam não está tanto na contestação a essa lista prévia (que é, em limite, constituída pelos ramos das ciências humanas atualmente aceites) mas na prática da escrita académica ou científica como fuga a toda possível constituição de uma autoridade a partir dela. Conceber o próprio projeto de investigação é procurar um domínio do conhecimento de forma suficientemente livre e desinteressada, isto é, imaginar e desejar um objeto de investigação.

Como não se espera que seja a Universidade a pedir ao investigador o seu desejo, mas apenas a sua aplicabilidade a um programa, a convocação que nunca é feita deve ser deslocada inteiramente para a escrita e para a sua prática. A pergunta que instaura a pesquisa só torna obrigatório o cumprimento metodológico a que a investigação se propõe (tornar o discurso inteiramente homogéneo ao objeto de que fala, diz Barthes). Nada deste programa em ambiente universitário tem a ver com espontaneidade e muito tem a ver com reflexividade e com o jogo. Torna-se necessário jogar, com a chamada escrita académica ou científica, um jogo em que a pertinência do objeto, tão verdadeiro quanto é possível reunir provas acerca dele, tão real quanto é preciso escavar o fundo sob o qual as provas materiais da sua existência se dispersam, se afirma pela escrita que o constrói. E que descreve não só a realidade material do objeto, mas que, ao existir, o faz acontecer. Nesse sentido, o objeto construído é tão verdadeiro quanto é suportado em provas e bem documentado, e tão intempestivo na sua aparição quanto a escrita é produtora do que de si próprio afirma.

O que quer dizer intempestivo na aparição? Quer dizer que o movimento da escrita aparenta encaminhar-se para um sentido, aquele que conduz o estudante para a sua afirmação pela escrita, e que, à custa da própria força de escrever e de fundamentar o argumento que habita a consciência, pode encaminhar-se para uma derivação, divagar e, sem trair o projeto de pesquisa e a pergunta inicial, ramificar-se em direção ao desconhecido. A demanda da escrita, um aliciamento que envia em direção ao encanto das Sereias, a escrita que nos convida a desparecer nela, exclui, em primeiro lugar, um objetivo e um destino precisos e não é meramente técnica, mas nem por isso é preciso negar-lhe a qualificação científica ou académica. É coerente afirmar a impossibilidade de saber, no início da pesquisa, quando, onde e como vai ser possível definir o ponto de chegada, contingente apenas a exigências exteriores (é preciso concluir o trabalho) para que a escrita permaneça o motor da investigação e uma promessa infinita.

Não se trata exclusivamente de escrever, mas de, passando pela experiência da escrita, ela poder narrar o seu próprio caminho, as hesitações, imprevisibilidades e problemas, resolvendo assim um dos mistérios da narrativa. "A narrativa não é o relato do acontecimento, mas o próprio acontecimento, o acesso a esse acontecimento, o lugar aonde ele é chamado para acontecer" (BLANCHOT, 2005, p. 8). Michel Foucault fala, por isso 
mesmo, do "descaminho daquele que conhece" para poder continuar a pensar, da tarefa do "trabalho crítico do pensamento sobre si próprio" para exercitar um pensamento que, em potência, só existe ainda fora do pensador, e de "pensar a própria história" para "libertar o pensamento daquilo que ele pensa silenciosamente e permitir-lhe pensar de um modo diferente" (FOUCAULT, 1994, p. 14-15).

\section{Em direção ao texto...}

Um trabalho académico servido por tais considerações sobre a escrita pode passar por pretensioso e os jogos mais ou menos fantasistas que a introspeção fabrica podem assemelhar-se a futilidades. É preciso, pois, afirmar que a liberdade de pensamento que se projeta, ao fim de muito esforço, cansaço e desilusão, não radica em nenhuma das alegadas liberdades que circulam no espaço mundano mas "no regresso das palavras, do jogo de palavras, dos nomes próprios, das citações, das etimologias, das reflexividades do discurso, das paginações, dos brancos, das combinatórias, das recusas de linguagens", isto é, como diz Roland Barthes, numa "liberdade que é encenada" para regressar ao texto (BARTHES, 1987, p. 81).

A exortação ao investigador para expor, a cada momento, a sua metodologia tem a razão de ser neste regresso ao texto. $\mathrm{O}$ texto barthesiano assume que as camadas históricas dos discursos nelas depositados são problemáticas, isto é, não podem ser vistas como resultado de uma realidade que possa ser assumida, e que os discursos que habitam essas camadas não são neutros. O texto é uma arena metodológica esculpida pela linguagem e açoitada pelos ventos dos discursos contrastantes, que um dia será concluído, aferrolhado mesmo, num produto acabado, e cujo movimento até ao seu fecho é o da "travessia" (BARTHES, 1987, p. 56). O texto é a grande travessia, para gente do risco e do movimento ousado, como dizia Blanchot acerca dos navegadores que as Sereias silenciosamente aguardavam. O texto atravessa as obras, é um estado experimental da escrita, é, como diz Barthes, "o que se situa no limite das regras de enunciação" (BARTHES, 1987, p. 57), atravessa as obras do mesmo modo que se perseguem no oceano seres imaginários. É, por conseguinte, um trabalho, uma dedicação, um estar-a-fazer. Ele não está vinculado a um discurso, está a tentar manter-se à tona no redemoinho dos discursos existentes, que o pesquisador convoca para o seu ofício para com eles montar um aparato.

Desaparecer na escrita não é um incentivo à despersonalização do estudante e do investigador enquanto pesquisador, é a liberdade de convocar discursos que convidam ao anonimato dos autores das obras. Por mais canónicas, por mais pertinentes, por mais convenientes, elas estão ao serviço de uma confeção. "O texto é um tecido" (BARTHES, 1987, p. 58). As obras não são para levar a sério, já que nelas só se pode pescar fragmentos. Se a obra é assinada por autores e frequentemente habitada por deuses, o texto é um campo metodológico, onde sobressaem a sua delimitação, o seu objeto, as suas fontes, o seu argumento, a sua legibilidade. O texto é um conjunto de enunciados em aberto, não existindo nele um significado verdadeiro para captar, mas o campo exploratório em que a descoberta 
de combinações, transformações e deslocamentos permite escapar ao peso de autores tutelares.

O texto pode cumprir a promessa de uma escrita infinita, não porque ela seja indizível ou intocável, mas porque a sua prática pode ser inebriante. Sentir a alegria que dá o poder da escrita, como diz Blanchot, não é, obviamente, um recurso disponível apenas para a escrita chamada literária. Seria incompreensível. O investigador deveria usar a linguagem para objetivos apenas comuns, exteriorizando-a à própria experiência de escrever? Ganharia, com isso a decência de habitar um campo neutro e colocaria a própria pesquisa como resultando dele, como se não houvesse erosão alguma nem descoberta no caminho percorrido pela escrita? A pesquisa académica e científica pode procurar os instantes em que a dedicação à escrita se comunique inteiramente com a procura de uma prática. Evidentemente, tal escrita não se apresenta como artifício da pesquisa, ou apenas como seu mecanismo de comunicação, antes se envolve com a própria pesquisa, transformando o seu rumo e resolvendo-se nela. $\mathrm{O}$ que se resolve nela é o texto, o jogo de representar o que há de mais fragmentário, a recolha de excertos, de ideias, de frases, num aparato contínuo.

Claro que os fragmentos a recolher são de uma linguagem conhecida, a sua combinatória é que não. Aproveitar tudo o que se ouve, se pertinente, para enformar o objeto da pesquisa, qualquer que seja a proveniência, remete o estudante para a condição de fabricador. Um fabricador está em melhor posição para desdenhar o fantasma dos grandes autores e o receio dos grandes professores. O texto é um intertexto.

O intertextual em que todo o texto é apanhado, visto que ele próprio é o entretexto de um outro texto, não pode confundir-se com qualquer origem do texto: procurar as 'origens', as 'influências' de uma obra é obedecer ao mito da filiação; as citações de que um texto é feito são anónimas, inidentificáveis” (BARTHES, 1987, p. 58).

Não existe nenhuma origem, por definição inacessível, à espera do estudante em Educação ou em outro ramo das ciências humanas, nenhum começo fundador que explique uma tradição duradoura, começo ao qual, magicamente, se possam vincular todos os desenvolvimentos posteriores, e um fio contínuo que explique o tempo atual. Tal como o texto académico ou científico reúne fragmentos de toda a origem, para formar um compósito, também a origem sonhada é parte de um texto fragmentário, que nunca ganha a gravidade de uma explicação linear e que só pode submeter-se ao princípio da descontinuidade. A descontinuidade, longe de ser um desastre, é um "conceito operatório" (FOUCAULT, 2008, p. 10). É possível ao pesquisador afirmar, sustentado na evidência histórica, que algures no tempo irrompeu um acontecimento (os estudantes passaram a organizar-se em classes homogéneas, quanto à idade e ao desenvolvimento mental, por exemplo); que essa irrupção longe de não ser inteiramente compreendida por se ligar a uma origem que não mais seria possível ver com clareza, é afirmada pela dispersão dos discursos existentes (os discursos oficiais sobre a organização da sala de aula, os tratados de educação, as opiniões dos especialistas no espaço público). Esta discursividade que se polariza não indica um ponto 
rumo à tradição, mas um sistema dispersivo de enunciados. Deixa de pisar terreno conhecido para começar a ouvir o melodioso canto das Sereias, num movimento idêntico àquele que faz procurar o texto em vez do autor.

Não existe, para ser procurada, nenhuma noção de tradição, ou seja, um conjunto de fenómenos sucessivos, que se uniriam pela sua identidade e que, aparentemente homogéneos, construiriam a própria sucessão. Pelo menos, não existe uma tradição que não possa ser procurada nas razões que a sustentam, as quais, quando aclaradas, tendem a pô-la em causa. Também não existe uma categoria chamada influência, a que os estudantes em Educação teriam de fazer sujeitar inicialmente o seu objeto, a influência que filiaria indivíduos em outros indivíduos e obras em outras obras, e que permitiria dispensar de saber de que são feitos obras e indivíduos, na sua aparente continuidade. Origem, tradição, influência não são conceitos não usáveis, mas só proveitosamente integram a narrativa se os discursos que se lhes referem prosseguirem a sua mais deliberada descrição, naquilo que poderia ser chamada uma crítica da linguagem.

A liberdade prometida é, pois, uma liberdade inteiramente construída pelo estudante na luta com a intangibilidade da origem, com o peso da tradição, com os fenómenos de causalidade da influência e com todos os invariantes históricos que supostamente se apresentam já na sua formulação definitiva (o Estado, a Educação, o poder, etc.). Constituise como uma liberdade radical contra as crenças pessoais, contrária à continuidade das ideias adquiridas, e como um conflito consigo próprio. O objetivo de toda a investigação e o propósito da pesquisa, universitária ou não - poder pensar o que não se pensava - só pode conceber-se como um combate em que apenas cada investigador está à altura de encontrar a resposta que lhe convém. É porque a narrativa "exclui o desenrolar simples de uma história" (BLANCHOT, 2005, p. 32), que ela pode vir em auxílio do estudante. Ela exclui a continuidade dos tempos, como se fossem homogéneos, e a ligação dos acontecimentos no sentido da sua elucidação presente e acabada, como se a atualidade fosse o ponto culminante da história. Ela desfaz, por assim dizer, "a cronologia contínua da razão" (FOUCAULT, 2008, p. 9). A soberania da razão, a robustez da obra, a indissociabilidade do autor em relação à sua escrita, todas essas unidades podem ser chamadas a dissipar-se em presença da trama discursiva que o pesquisador recolhe, recorta e recoloca em jogo.

As velhas relíquias da história permanecem à disposição do pesquisador não exatamente para serem salvas e salvaguardadas, mas para a sua recomposição. Respiga-se os tesouros antigos para com eles compreender a verdade que também nos atinge e, por isso, o movimento da escrita é incerto e infinitamente desdobrável. Se as velhas relíquias são, para o pesquisador em Educação, documentos (mesmo que sejam monumentos), é preciso agrupálos, relacioná-los, organizá-los e fazê-los falar, não a partir do seu valor intrínseco, mas questionando-os na sua intimidade. Ao perguntar quem, nos discursos, tem direito à fala e investido de que estatuto; de que lugar fala e que legitimidade tem; se fala interrogando ou afirmando uma certeza por demais afirmada, é-se convidado a ouvir como as vozes do passado "manifestam a sua dispersão" e rejeitam qualquer "função unificante" (FOUCAULT, 2008, p. 61). A pesquisa dá-se à dispersão. 
Não se trata de não temer nenhuma lei nem os constrangimentos associados às práticas de normalização, hierarquização e exclusão que fazem parte da máquina escolar, apesar de todos os discursos sobre autonomia e liberdade. Trata-se de afirmar que, se o trabalho da junção de fragmentos está por fazer, é porque há uma probabilidade de vir a ser original e de constituir uma ordem de relações que só é possível pelo manuseamento pessoal. A liberdade, pois, radica na vontade de perguntar até que ponto é necessário escrever, se escrever sustenta o dia e se, ao escrever, o pesquisador se põe à prova.

\section{...e, resolutamente, em direção à escrita}

Para lá dos constrangimentos enfrentados pela circunstância de a linguagem lhe preexistir, por usar e se determinar na linguagem que o faz falar, o estudante que pesquisa em Educação enfrenta outro grande limite. $\mathrm{O}$ facto de o seu objeto de pesquisa ser, por assim dizer, ele próprio, ou os seus antepassados em comparação consigo, como produto da máquina educativa em relação à qual se formou, na qual aprendeu a pensar, a interrogar-se e a problematizar. Desaparecer na narrativa que tece significa, também, figurar involuntariamente como uma aparição, em que a figura do escrevente se deve a toda a experiência passada de estudante. Desde a infância que a experiência da escola é ensinar a ler, e não a pôr em jogo o par leitura-escrita como mútuo alimento, não a da leitura e da escrita sob a mesma densidade e aprofundadas na mesma superfície, mas a da precedência da leitura sobre a escrita.

Escrevemos o que lemos, escrevemos em conformidade com o que lemos; somos escolarizados para nos confinarmos à posição de leitor e a idealizar o que o outro escreve como génio e as suas realizações [como] exemplos de transcendência (Ó, 2017, p. 128).

Barthes afirmava que a presença do texto (não da obra) podia abolir a distância entre a escrita e a leitura.

Nenhuma transformação ocorre e nenhuma deslocação íntima prepara o estudante emancipado por tentar entender o que os antigos autores quiseram dizer, nenhum entendimento que não o da reiteração se realiza através da incultura do resumo e da morbidez do comentário, não existe democracia alguma em instruir a criação como repetição. Se o saber é a repetição do que já foi dado, por que haveria o estudante de querer pesquisar ou escrever a sua pesquisa? O que tem a ver o comentário com a descoberta do texto em crescendo, progredindo a partir de uma palavra, uma frase, uma citação, desses centros primitivos que urge alimentar, ir espessando-os e ganhando com eles o próprio corpo de escritor?

Rodopiando em torno desses centros, progredindo ao sabor do trabalho e da desilusão, essas frases já estabilizadas esperam o encontro amoroso com o escritor, a sua transformação pelas variações do espírito. Trata-se de interpelar o encargo da escrita que se pode realizar 
na Universidade ou em qualquer outro lugar, como uma espera, onde volteiam todos os fragmentos de toda a recolha possível, dos autores que, canónicos ou anónimos, fazem o estudante ter vontade de escrever e progredir no seu argumento. Dirigir tudo para a escrita, como recolha dos instantes fragmentários colecionados, e dirigir-se resolutamente para a escrita, como trabalho de transformação isomórfica com o objeto pesquisado. Um programa doutoral não pode recusar ao estudante a busca do que é útil e atraente para si. Torna imperioso construir, em torno do que é agradável como objeto de estudo, uma convicção em forma de fortaleza, pois a sisudez dos estudos superiores - ou seja, o poder que deles emana como instituidor das forças conservadoras - não reserva muito espaço para a alegria contagiante. Se esse espaço da escrita contagiante tiver lugar, ele é habitado por uma impaciência (o desejo íntimo da sua concretização) e pelas formas da apropriação dessa escrita pelo escritor (nem impaciência, nem rapidez, nem produtividade ou vertigem, mas o trabalho incansável de recolha e da perseverança na fabricação).

\section{Viver fora do tempo}

As comunidades que se juntam em torno de propósitos semelhantes, mantendo a individualidade de cada participante, parecem poder suprimir, em certos momentos, a passagem do tempo, vivendo a experiência de um tempo fora do tempo. Experimentar o tempo como espaço vazio, como diz Blanchot, é um exercício tão antigo como o pensamento, que deve ser preenchido pela procura do conhecimento. As comunidades de reflexão e trabalho têm o aspeto de seminários ou de grupos informais de estudantes nas universidades.

A metáfora do tempo fora do tempo, como propósito de encontro entre mestre e estudantes, ou de grupos de estudantes, toma o encargo de pensar o presente como o mais custoso, o tempo por definir, e o que fazer ao tempo indefinido, quando se está perante a obrigação da relação, de uma pedagogia relacional. É, também, a afirmação de que, nessa relação, a procura da escrita situa, a todo o momento, o mestre e os estudantes, ou os grupos de estudantes, num eterno presente, que é o tempo da enunciação. Escrever é um ato performativo sem nada que o preceda nem nada que o espere. Para os estudantes é um encontro, em primeiro lugar, com potências do pensamento como as convocadas para este texto, Barthes, Blanchot e Foucault, entre muitas outras. Um tal encontro, com o que Deleuze chama "intercessores", proporciona o enfrentamento com um grupo de autores árduos, canónicos, durante o qual o estudante pode colecionar ideias, fragmentos ou a sua inteira rejeição, mas cuja visitação, com o passar do tempo, constitui um arquivo.

E possibilita a leitura desses autores em grupo, experiência irredutível a toda a hierarquização, entre os presentes, acerca das falas ou silêncios, e do seu brilhantismo ou assertividade. Tal como defendem nos seus escritos muitos dos mestres que são convocados para serem lidos nesses encontros, talvez nos grupos de trabalho se experimente um lugar exterior ao poder, ao convidar os presentes a partilhar, momentaneamente, um espaço entre iguais, em que a vinculação, no espaço relacional, é o exercício da leitura para poder escrever - e, no desenvolvimento do trabalho, a inversão dos termos como desígnio, escrever para 
poder ler. Perante a inquietude da ausência de hierarquia, contestada e reclamada, é-se atravessado por uma respiração em que a presença profunda do ato de falar vale tanto como o silêncio reservado.

Experiência antiga, multiforme e universal na Universidade, os grupos de pesquisa e os seminários enaltecem a comunidade que procura. A formação das categorias competitivas nas quais professores e estudantes se educaram, as histórias de emulação dos professores aos estudantes narradas desde há duzentos anos, servindo a economia da hierarquização social, devem observar as suas horas de pausa (já que nunca desaparecem), e, em face da procura da necessidade que faz escrever, as suas horas de sossego (pois o peso da escrita deve poder transformar-se numa leveza procurada) e recuar em face das dúvidas, problemas e hesitações que o enfrentamento com os autores produz. É preciso alcançar o que a fixação da escrita não permite, uma vez que as palavras ditas são essa leveza procurada pela escrita. Assim se estabelecem comunidades provisórias de iguais e se continua o desígnio pitagórico, o de que a fala do mestre pode e deve ser continuada pelos estudantes, não estando presa à injunção canónica do pensamento do mestre. Também se cumpre a ideia da curiosidade e do entusiasmo infinitos que a pedagogia como trabalho em conjunto deve observar, o que leva o historiador António Nóvoa a afirmar que os mestres só podem ensinar bem o que ainda não sabem.

Nos encontros grupais, a escrita tem a sua origem e originalidade na palavra oral, permutada por se repensar o pensamento, e a escrita que paira dessa forma forma-se primeiro na consciência de cada um. Embora sejam apresentados em obras, nos grupos de pesquisa os autores são texto, fundamentalmente. Se o texto, como diz Barthes, "pratica o recuo infinito do significado" (BARTHES, 1987, p. 57), ele não é apresentado para ser compreendido, mas para que se possa variar a possibilidade da resposta ao problema de investigação. A preocupação com o novo, com a criação, talvez esteja mais do lado dessa variação, que o futuro intertexto do estudante quer alcançar. A inovação não se deixa prender nem a uma precedência nem propriamente a uma hierarquia, ela não observa uma ordem cronológica, ela não obedece a um aprofundamento hermenêutico, ela simplesmente circula entre decursos de textos, entre passagens que os desnivelam e os recompõem.

"A experiência de participar num seminário permite a cada um dar-se conta do que efetivamente conhece, de que numa qualquer ocasião terá possibilidade de enunciar e argumentar os seus problemas e pontos de vista" (Ó, 2019, p. 486). Tem como grande papel convidar os estudantes a criar os seus intercessores, mas convidar tanto a conhecê-los e a colecioná-los, quanto a fabricá-los. "O essencial são os intercessores. A criação são os intercessores" (DELEUZE, 2008, p. 156). Deleuze afirma que os intercessores, quando existem, podem ser tão fictícios quanto reais: pessoas de carne e osso, como o mestre que conduz o seminário; autores como os que são convocados; e também seres animados ou inanimados, coisas, plantas ou animais.

Por causa deste tempo necessariamente pouco apaziguador, em que a fala não se destina a terminar um argumento, o estudante não deve exigir menos do que procurar o conhecimento que lhe convém, e que lhe proporciona alegria. Exigir o lugar que lhe convém como meio para realizar a sua expressão, e para encontrar, na escrita da investigação, a essência do que 
lhe escapa como habitante da contemporaneidade. Mas essa essência é uma espécie de afirmação negativa, que reside onde a autoridade não se dá.

\section{0 arquivo}

Os domínios do saber em direção aos quais se dirige o estudante, e que não são exatamente úteis, mas úteis à descoberta, podem constituir uma grande biblioteca, mas a pesquisa trata, exatamente, de entre as centenas de referências disponíveis, de lidar com uns poucos de livros. Construir um arquivo é diferente de edificar uma biblioteca. A biblioteca virtual está, em princípio, disponível, abrindo o espaço mental necessário ao recolhimento do ato de coletar. $\mathrm{O}$ arquivo é tudo o que interessa ao estudante, sob a única forma utilizável, o fragmento; a biblioteca é tudo o que pode interessar e, portanto, inconciliável com a vontade de pesquisar. O arquivo, pouco numeroso, é como que fluído, e pode constar de um conjunto de notas, a biblioteca é um peso.

O estudante procura no arquivo tanto a referenciação como a forma de expressão. Escrever com alguém, para tentar evitar o desgaste da solidão, e poder perder-se no próprio pensamento na companhia de quem já pensou, é uma experiência determinante. E, como os espaços coletivos e de recoleção teórica comum supõem "a prioridade absoluta do escrever sobre o ler" (Ó, 2019, p. 383) [itálico do autor], o estudante já chega escritor ao início da escrita que quer executar. A coleção de fragmentos dos outros, na medida em que seduzem para pensar e escrever, abre ao escritor mais inexperiente a possibilidade de se distanciar dos autores como causa e consequência do que produzem. Também esses autores tiveram de dissociar a obra e a pessoa para encontrarem a escrita e também eles tiveram de desterrar o "império do Autor" (BARTHES, 1987, p. 50). A escrita a partir de um arquivo remete-a para uma desconformidade entre o sujeito que escreve e a autoria do escrito, no sentido em que “a escrita é destruição de toda a voz, de toda a origem” (BARTHES, 1987, p. 49). Esta espécie de diluição de si como procura, que é uma atração para um magma sem identidade e o eterno presente que se anuncia na escrita, não é uma fragmentação da personalidade, é o exercício da mais pequena tarefa, a ativa procura do fragmento, como domínio sobre si para escrever.

A construção de um arquivo no campo das humanidades torna inteligível o trabalho histórico de elaboração discursiva, que tende a procurar não a clareza de um ponto que parecia enevoado, mas a sustentar um ponto de vista. Ele dá-se, pois, à dispersão da própria contingência em que foi formado, na certeza de que o discurso constrói o próprio assunto de que fala. $\mathrm{O}$ investigador certamente que trabalha para compulsar a verdade sobre o passado que se lhe apresenta, mas a passagem do arquivo para o texto, isto é, a passagem da fabricação de uma massa inerte de documentos para a sua fragmentação como se fosse um contínuo, não permite escapar a toda a intencionalidade nem da linguagem usada nem do pesquisador que é o seu veículo.

A escrita académica ou científica pode ser, ao mesmo tempo, domínio (determinação do objeto, injunção da procura) e desejo e derrapagem (ir para onde o movimento levar), para tentar acercar-se do ponto onde só a linguagem atua, como diz Barthes. Uma diluição de si 
na escrita não será paradoxal mesmo na Universidade, se ela se realizar a partir dos instantes coletivos de uma certa ociosidade, e ajudar a construir em grupo o corpo do escritorinvestigador. A escrita exerce-se em cima de séries e não de totalidades (bibliotecas) e esta é a única economia produtiva que pode ser levada a sério na escrita académica. Estabelecer séries significa descrever para si a pertinência de uma série, onde ela deve começar e onde deve acabar e que relações se movem no seu interior, distinguir "o que é pertinente do que não é", definir “unidades", estabelecer "relações" (FOUCAULT, 2008, p. 7). A metodologia organiza, evidentemente, a pertinência das séries. O que quero saber joga-se em que tabuleiros, ao certo? O que se liga, o que se correlaciona, o que é dominante e o que deixou de ser? Não se trata de unir o que se liga e o que se correlaciona a um princípio e a uma determinação únicos, mas fazer aparecer os diversos princípios e determinações nas suas proveniências e gradações. Aumento e intensidade são movimentos tão válidos nessas séries como intermitência e erosão, na procura do que parece dissonante em relação ao pesquisador e ao seu mundo, ao que aparenta estar longe, ao que se apresenta como teatro inapresentável.

\section{Escrever bem, abandonar-se ao estilo}

Existe uma diferença sensível entre a necessidade de construir, fragmento a fragmento, uma série ou séries documentais, isto é, um arquivo para ser analisado, num contexto da preparação de um artigo ou de uma tese; e saber que o texto a produzir, para além de tratar o conteúdo do arquivo, integra como conteúdo a própria linguagem que usa. Ambas as tarefas são urgentes, ou seja, em ambas reside o projeto a realizar. A linguagem está preenchida por todos os conteúdos que a formaram e é forma e conteúdo. Barthes caraterizou o desafio que se abriu à escrita, a partir da rotura de meados do século XIX, a densa rotura com a escrita clássica. Um estilhaçamento das escritas do mundo, que corresponde à afirmação das escritas literárias no sentido de "fazer explodir o fechamento frástico" (BARTHES, 1987, p. 115), desobriga de escrever bem, cuidadosamente, ciosamente, e de forma idêntica; dispensa de ser-se percebido na justeza das afirmações e desobriga a forma de escrever de servir apenas o conteúdo. Não existe mais uma uniformidade procurada para beneficiar e iluminar o argumento, a mensagem.

É verdade que o estudante que tem geralmente de apresentar-se a um juiz no final da pesquisa, deve escrever segundo uma certa coerência, de acordo com uma clareza e em direção a uma finitude (estado da arte, objetivos, metodologia, etc.), mas pode autorizar-se a escrever sem procurar uma uniformidade? Quer dizer, pode autorizar-se a não escrever bem? Questão difícil, mas que não tem remédio se a escrita tiver de justificar-se de ser como é. A escrita justifica-se pelo movimento que interpõe entre o escritor e o objeto de investigação, ao pretender procurar uma verdade. Essa verdade, que não é soberana, destina-se a obscurecer a verdade original do escritor, isto é, a desarmá-lo, a confundi-lo, a perdê-lo. É esse o movimento que mergulha o escritor em si e é esse o exílio que observa face a algo que quer captar. 
Talvez o exílio pareça um determinismo semelhante ao determinismo que se quer combater com a pesquisa. Se só se pode afirmar por meio da linguagem, a linguagem determinaria o impedimento da própria afirmação, ao circunscrevê-la. Esta escrita correria o risco de ser não só pretensiosa como limitadora das possibilidades de pensar. Mas não é por habitar a linguagem que os seus meandros se aclaram e aprofundam? Não é por pensar e especular que o próprio objeto de investigação se desloca em um sentido não previsto, mesmo que seja para uma espécie de limite? O investigador testa os seus limites na investigação, isto é, as suas crenças, não porque vá encontrar nelas a sua individualidade, mas porque a vontade de escrever rigorosamente lhe dará a saber que é obscuro o caldeirão de onde elas provêm. Os seus limites são testados, enfim, porque o acabamento do texto corresponde a uma incompletude do gesto da escrita. A escrita destina-o a desconhecer o gesto da escrita como finalidade, a desconhecer a escrita como mestria. Pesquisar não para que a escrita devolva uma racionalidade tranquilizadora nem respigar documentos para construir um refúgio reparador é, talvez, uma hipótese para pensar o que ainda não foi pensado, isto é, para concluir que "aquilo que existe para ser pensado é, no pensamento, o que dele se afasta" (BLANCHOT, 2005, p. 56). A escrita como exílio transitório, que afasta o olhar da atualidade, abre a possibilidade de contemplá-la enquanto é atravessada pela vida.

Tal escrita permite pensar o estilo na escrita académica ou científica, não tanto como o que distinguiria o escritor individualmente, evitando-se assim a uniformidade em torno da procura de um estilo, mas o que singularmente apontaria para o gesto implicado na pesquisa. "Mais profunda do que a diversidade dos temperamentos, dos humores e mesmo das existências, é a tensão de uma busca que coloca tudo em questão" (BLANCHOT, 2005, p. 300). O estilo não é a procura da idiossincrasia que tornaria restrito o trajeto do pesquisador, antes a escapatória possível para que o trajeto se possa fazer desconhecido. Quando o trajeto da pesquisa resulta em algum desconhecimento de si, pelo desconhecimento do que se tinha como evidente, o resultado não é a existência de um estilo, é a inexistência da personalidade que se julgava ser, uma espécie de expatriamento de si no ato de escrever.

A inexistência de um estilo, procura negativa que talvez devesse ser cara ao pesquisador, pode procurar-se nas acidentalidades afirmadas na sua escrita, nos argumentos que estão a caminho e que não encontram uma finalidade senão para explicarem o sentido das múltiplas hipóteses da investigação. O pesquisador enfrenta-as constrangido porque é preciso, cedo ou tarde, proceder ao fecho do argumento. Mas é possível, fechando o argumento, afirmar a inconsequência de quem o afirma e recusar a perenidade do fechamento. Barthes chama a atenção para o que é o estilo, individualização que é produto da biologia e do passado do escrevente, que ele não domina, que lhe escapa, que ele não escolhe e que se enrola nele com a mais profunda solidão. É porque o estilo, como a língua, antecede o escritor, porque esse implícito de forças ativas e muito dissimuladas joga contra o escrevente, que "a identidade formal do escritor só se estabelece verdadeiramente no exterior da instalação das normas de gramática e das constantes do estilo" (BARTHES, 2006, p. 17). Não é que o estilo não possa ser procurado, ou não possa ser sagazmente avaliado o tom da escrita pelo estilo empregado, é porque o estilo é uma intimidade pouco acessível - como é a herança cultural para uma nação - que é possível tentar distanciar-se dele para imergir na procura íntima da escrita. $\mathrm{O}$ 
estilo é, então, "essencialmente um processo citacional, um corpo de inscrições, uma memória (...), uma herança baseada na cultura e não na expressividade", que levaria a considerar a sua riqueza como o "entrançado [que] forma o texto" (BARTHES, 1987, p. 117). Essa riqueza mostrar-se-ia por inteiro na pluralidade de citações e na capacidade apelativa de atrair fragmentos ao centro de gravidade da pesquisa.

Para lá das potências que amarram o escritor à sua história e o prendem a toda a espécie de tradições, contra o "rumor que muda de antemão tudo o que podemos dizer" (BLANCHOT, 2005, p. 302), existe a afirmação do estudante e do escritor, o gesto em que a hipótese é a necessidade de encetar a destruição da herança que o constitui. Contra a forma de transmissão do poder que é a herança, o exercício da escrita pode revelar-se, para o estudante, uma suspensão, um tanto ilusória, dos poderes que o constituem e que constituem a linguagem pela qual se expressa, o lugar em que a grande travessia se dá: o escritor convoca os discursos e, esperando, procura pela escrita que os articule.

A narrativa alcançada a partir da fabricação de um texto académico deve ser entendida como o movimento desse texto que percorre um vazio, ou seja, um espaço por definir em direção a algo que é desconhecido e que não é dado inicialmente. Aquele movimento teria por função esvaziar o escritor o mais possível das condições históricas em que escreve, os mecanismos pedagógicos que o formaram e a herança que herdou, a condição social, económica e cultural que é a sua. Se é pelas formas discursivas que esses mecanismos exercem o seu poder, e que elas enraízam o escritor na linguagem, é pela escrita que a linguagem do poder será questionada. Neste sentido, a narrativa é o que ainda não existe e a escrita académica em ciências humanas, ou seja, na formação do conhecimento histórico e empírico, é a procura de uma audácia, não porque cada escrita quer conceber-se como diferente e aí se jogasse a identidade do escritor, mas porque a escrita se abre ao questionamento do que ainda não pensa.

Compreende-se, desta forma, que, para o estudante, a urgência de procurar o que se quer saber possa ser tão determinante quanto perceber o que leva a escrever. Porque se trata de não dissociar escrita e pesquisa. Ao escrever, o estudante parece encomendar-se a um destino (o juízo final da banca na Universidade) mas como a escrita não tem a ver com o consumo, e sim com a produção, o caminho que percorre não é o de uma aproximação aos outros, mas o de um distanciamento de si.

\section{Conclusão}

Circunscrita pela linguagem que a comunica, a pesquisa académica e científica em ciências humanas não se dissocia dela, tal como os seus enunciadores, estudantes e investigadores, não se desligam da biologia e da história que os constitui. Como a linguagem não é o feliz instrumento da expressão humana, nem a forma neutral de um fundo por preencher, a pesquisa académica e científica exerce o seu rigor construindo a pertinência de escolher o que se decidiu investigar, submetendo a leitura e a recolha ao único critério do enriquecimento do material empírico; fabricando uma companhia teórica, em que mestres, 
estudantes, seres e coisas inanimadas, se erguem do nada como uma coleção fragmentária de palavras, de frases e de sentidos, capturados para prender o pesquisador à impossibilidade de escapar ao canto mudo das Sereias; exercendo a teimosia de construir um arquivo em prejuízo do que é inadequado ao desejo, ou seja, a biblioteca, o "espaço que se visita, mas que se não habita", por ser contrário à delimitação, ao recorte e ao manuseio dirigido com à-vontade (BARTHES, 1987, p. 34); intimando-se a tentar conhecer o objeto por meio do desconhecimento do pesquisador, em que a transformação em curso é uma produção em direção à intriga da escrita; objetivando a pesquisa pela recolha, seleção e tratamento dos dados, pela explicitação dos intercessores, pela descrição das metodologias usadas e dos obstáculos encontrados.

A pesquisa não se oferece à denegação metodológica nem a nenhum relativismo abstrato, em que tudo seria possível. A pesquisa académica e científica exerce-se no encontro das comunidades de pensamento, exercitando o êxodo do próprio destino e um tempo como exterioridade; identificando as tiranias contras as quais a pesquisa se constrói, as teleologias, as origens míticas, as influências regressivas e os sujeitos soberanos; exercitando, finalmente, o estilo como procura, como intensão da investigação, como implicação do sujeito que investiga com o objeto da investigação, o enlace com a escrita e com o texto.

\section{Referências}

BARTHES, R. O grau zero da escrita. Lisboa: Edições 70, 2006.

BARTHES, R. O rumor da língua. Lisboa: Edições 70, 1987.

BLANCHOT, M. O livro por vir. São Paulo: Martins Fontes, 2005.

DELEUZE, G. Conversações. 1972-1990. São Paulo: Editora 34, 2008.

FOUCAUlT, M. A Arqueologia do Saber. Rio de Janeiro: Forense Universitária, 2008.

FOUCAULT, M. História da Sexualidade II. O Uso dos Prazeres. Lisboa: Relógio D’ Água Editores, 1994. Ó, J. R. do Fazer a Mão. Por uma Escrita Inventiva na Universidade. [Lisboa]: Edições do Saguão, 2019.

Ó, J. R. do Em defesa da Universidade: Autorreflexividade, dúvida radical e escrita do devir. Práticas da História. Journal on Theory, Historiography and Uses of the Past, Lisboa, n. 4, p. 127-194, 2017.

\section{Correspondência}

António Henriques: Doutor em Educação (Especialidade História da Educação). Áreas de interesse em que tem trabalhado na História da Educação incluem a educação artística, a ligação entre escola e herança cultural e a discussão parlamentar sobre educação. São, também, áreas de interesse a pedagogia do ensino superior e a escrita científica ou académica.

E-mail: antenriques@gmail.com

Texto publicado em Currículo sem Fronteiras com autorização dos autores. 